\title{
Medical Paternalism or Parental Autonomy in Decision Making: A Portuguese Study in Premature Newborns
}

\author{
Ernestina Maria Batoca Silva, Instituto Politécnico Viseu-Escola Superior de Saúde \\ Walter Osswald, Universidade Católica Portuguesa-Instituto de Bioética
}

\begin{abstract}
Health care providers and parents may have distinctive roles in the decision-making process regarding the care and treatment of premature babies. In this paper, we explore the process of decision making among doctors, nurses, and parents in premature care units (neonatal intensive care unites, NICUs) located in the central region of Portugal. Forty-one semistructured interviews with doctors, nurses, and mothers were conducted and analyzed. There is evidence that the medical teams provide a considerable amount of information to parents of premature babies, although sometimes unfavorable prognostic data are omitted. Mothers showed a high degree of confidence in the skill and knowledge of the medical professionals and accepted the latter's role in making decisions regarding the care and treatment of their premature babies. Only when invasive procedures or surgery were serious possibilities was something resembling written informed consent obtained. Ethics committees were seldom consulted. The results show that in the region surveyed, parents neither are invited nor appear to demand a role in making medical decisions that affect their babies. No conflicts between medical providers and parents were detected, suggesting that informed consent and the participation of parents in medical decisions regarding the care and treatment of their babies are not considered necessary or useful in this particular area by the respective parties, in contrast with the tenets of autonomy-based ethics.
\end{abstract}

Keywords: decision making, ethics, informed consent, paternalism, preterm infant

Of the 109,457 babies born in Portugal in 2005, 1,012 (0.92\%) had very low birth weight, weighing less than $1,500 \mathrm{~g}$ (Portugal 2006). The number of low-birth-weight babies has increased in recent years, and while low-birth-weight babies represent a relatively small proportion of all births, they account for approximately $50 \%$ of neonatal deaths. A significant number of these children also present at birth or later some level of disability (Machado et al. 2002). The care and treatment of these newborns have gradually improved, in large part due to advances in medical science and the efforts of health care providers.

Health care providers, however, face a number of difficult decisions and ethical issues when intervening to improve survival and prevent lasting damage among lowbirth-weight babies, especially when the parents are under stress and show increased vulnerability to the pressure of the situation (Maciel 2003; Neto et al. 2002; Pellico 2002).

We agree with Pellico (2002) in that that all decisions must have an ethical justification. Our particular concern, and the focus of this paper, is the role that parents play in making decisions concerning the care and treatment of their babies. To what extent do parents participate in difficult decisions as legitimate representatives of their babies? Is there a tendency among health professionals to reduce or ignore the parental role in decision making in the relevant questions due to benevolent paternalism? Do the parents receive complete and understandable information from the treatment team? Do conflicts arise between the health care providers and the parents concerning the best course of treatment for the neonates? If so, what role, if any, does the ethics committee play in resolving these conflicts?

This paper explores these questions, which have important ethical dimensions as well as practical consequences (e.g., in the outcome at discharge). Our study sheds light on the views of health care providers and parents, and its results can inform and improve the decision-making process in these settings.

\section{METHODS}

This is a qualitative study, of phenomenological nature, in the area of the constructivist paradigm (for further detailssee, e.g., Guba and Lincoln 1994; Rousseau and Saillant 1999). The study population was comprised of doctors and nurses in neonatal intensive care units (NICUs) of maternity wards and hospitals in the central region of Portugal and mothers of premature infants hospitalised at the time of the

Address correspondence to Ernestina Maria Batoca Silva, PhD, Instituto Politécnico Viseu-Escola Superior de Saúde, Rua D. João Crisóstomo Gomes de Almeida, 102, Viseu 3500-843, Portugal. E-mail: ernestinabatoca@sapo.pt 
study. This sample included all the doctors and nurses who occupied leadership positions (heads of units and teams).

Semistructured interviews, using questions approved by two independent reviewers (a bioethicist and a psychologist with academic positions), were used to collect the data. The inclusion criteria for doctors and nurses were that they be either heads or coordinators of service with more than 5 years of experience in intensive neonatal care. The inclusion criterion for mothers was that they were accompanying their premature infants and stayed in the unit for at least 3 days. Fathers were not interviewed because most of the time they were not available.

We conducted the interviews from January to April 2005; no time limit was imposed for each individual interview. The interviews were recorded on tape, transcribed by an individual not otherwise involved in the research, and professionally translated to English from Portuguese.

The interviewees were requested to participate by the first author; the objectives of the work were explained and confidentiality was guaranteed. Data were codified and categorized using the QSR NUD*IST (Qualitative Solutions and Research Pty Ltd, Non-numerical Unstructured Data, Indexing Searching and Theorizing) software package. The categories and scoring system are described in Silva (2007).

The boards of directors from the respective institutions provided authorization to conduct the study following the first hearing of their respective Ethics Committees.

\section{RESULTS}

\section{Characteristics of the Sample}

All individuals invited to participate in the study accepted and were enrolled. The sample consisted of 41 persons (13 doctors, 14 nurses, and 14 mothers). The professional group was predominantly female ( $81.5 \%$ women and $18.5 \%$ men). The health professionals all had at least 5 years of experience in neonatal intensive care units; the majority $(63 \%)$ had 10 to 20 years of professional experience.

The mothers were mostly 25 to 30 years of age and had completed secondary school. One-third of the respondents were single mothers and $64 \%$ lived in towns. All mothers had stayed in the maternity ward for at least 1 week. Although such characteristics may influence the parents' decision making (McHaffie et al. 2001), we did not correlate these variables with ethical attitudes, given the limited size of the group and the relative similarities of the answers among the mothers interviewed.

One baby was born in the 25th week of pregnancy and most were born between 26 and 28 weeks; all were premature and low-birth-weight babies. Two mothers reported that they participated in medically assisted reproduction programs.

\section{Decisions in Premature Infant Care}

All those interviewed stated that the mother of the premature newborn received information regarding the state of the baby's health, foreseeable development, and longterm prognosis from the first contact on until they were discharged. Some responses show total openness in communicating issues (e.g., facts, options, and difficulties). Generally, the information is given progressively. For example, D1 (doctor coded 1) stated, "We inform the mothers that the baby is in a very bad situation and explain why. When there is a lesion in which the percentage of sequelae is known, we tell the parents ... when we are sure we reveal the whole truth to the parents accordingly." Another doctor (D2) said, "They must be very well-informed, especially if the situation is serious. However, we do not tell parents that our team has decided to cease life supporting measures, but rather that the outcome is likely to be bad, thus, we prepare them and spare them the shock." One nurse (coded N11) was quite blunt, asserting, "We hide nothing. If the situation is bad, we say so. If there are future consequences to expect, they are told. They know everything."

Providing information to parents appears to be crucial whenever there are important decisions to be made, such as decisions on whether or not to resuscitate or to suspend certain types of care. Knowing the parents' opinion facilitates the decision-making process by the health care providers. For example, one doctors states, "We always take parents' opinions into consideration. Sometimes we know that we are putting a handicapped baby into the arms of the parents ... but that they wish to have him/her, whatever his condition" (D6). More explicitly, D7 says, "Whenever there is a question of stopping ventilation, we discuss this option with the parents; we hear their opinion and act accordingly." "We consider carefully the parents' opinion, we explain what is to be expected in the light of present scientific evidence, we tell them about our previous experience and try to explain everything; what they may expect in terms of survival or handicap" (D11).

However, some doctors feel that important decisions, such as whether or not to resuscitate, should not be made exclusively by the parents because "These are questions which require a scientific and teclnical background ... it is unacceptable to listen exclusively to the parental opinion" (D3). "They are informed, but it is not up to them to decide on issues such as whether or not to resuscitate" (D5).

Nurses consistently reported that parents are "heard" whenever invasive techniques or surgery are considered. "In recent times, parents are heard more often. Before surgery, for example, parents are always consulted" (N1). "When we speak about informed consent, we are thinking of invasive techniques, surgery ... in these cases, the parents' opinion is sought" (N4).

The role of parents in decision making was an important topic in our interviews. We found that no consensus could be reached by the health care providers on the matter of parents' participation in decision making. The doctors' responses were quite often ambiguous, a situation that the interviewees were aware of and that embarrassed them, prompting them to give this question careful thought above and beyond their initial responses. In fact, we obtained statements such as, "We try to explain the situation, so that they may grasp its meaning and hope that they participate in the decision... but the final decision is always ours" (D4). On the other hand, 
D9 is of the opinion that "parents are informed, of course, but in acute and difficult clinical situations how can they participate? It is too hard for them." "No, they [the parents] do not participate in decision-making, although they are always informed, they are informed about the need for treatment and how long it will last, they are given the prognosis in relation to a certain type of treatment, yes we always inform parents" (N4).

Another nurse (N14) thinks that there is a need for improvement in this area: "There is a need for us to grow, to accept parents as partners, to integrate them in the decision-making process, to recognize their parental value."

Thus, our study shows that parents are not always allowed to participate in decision making, or it is not always feasible for them to do so, but it is customary to give information and an explanation after the treatment has been adopted: "We inform the parents about our medical decision, we don't ask them to decide" (D1). "Parents are informed about therapeutic decisions; they do not usually participate in them" (D3). "Decisions are taken by the team ... parents are then informed ... the final decision is always ours" (D4). "The medical team takes decisions, and subsequently informs the parents ... parent participation in making decisions is limited to very restricted situations" (D7).

The nurses' responses are consistent with those provided by the doctors, as shown by these examples: "No, normally they do not participate ... they are informed about the decisions" (N3). "Well, participation in decision-making is somewhat illusory ... parents are informed about the decision" (N4).

What reasons do health care providers cite for their decisions to generally exclude parents from decision making in critical situations, such as whether or not to resuscitate? In our enquiry, the main reason provided by both doctors and nurses was the defense or protection of parents, sparing them the responsibility of such difficult choices. For example: "We try to inform them of our decision, thus freeing them of the stress and heavy responsibility of deciding if and when ventilation is to be interrupted ... this would be too painful a burden to bear for the rest of their lives" (D1). "Decidedly, this is too heavy a moral burden for their future" (D2). "I consider it to be of extreme emotional violence to ask parents what they want us to do" (D12). "No, parents should not have to shoulder the weight of deciding ... to decide if ventilation should be interrupted is too hard for them" (N1).

Parents may prefer not to get involved in the situation; this has also been cited in support of the argument against parental participation in vital decision making: "It also depends on parents' sensitivity, because there are mothers who prefer not to talk when the situation is serious. They do not ask questions, they remain in silence and it is not our task to force them into talking. We say: 'when you think it is appropriate, we are ready to talk with you. Whenever you wish" (D6). "Well, parents receive information, unless they do not wish to. Such cases happen, parents are absent, they do not ask for information" (N10).

Parental participation may also be hampered by a low level of education or an inability to understand; these factors can make it difficult to communicate with parents and to inform and obtain consent. "What often happens is that our information is not understood by parents, or they do not want to understand because the facts are unpleasant, and sometimes we explain over and over but still we get asked the same questions and people still say that nobody has told them anything, which is not always the case" (D1). "Sometimes we explain and believe to have been very clear and on the following day or a couple of days later we realise that they really did not understand at all or they understood very little or misunderstood" (D13). "But, of course, this also depends on how much knowledge the parents have and even of their sociocultural status" (N14).

We also found that parents often trust doctors to such an extent that doctors consider it unnecessary to consult them during decision making. "Seldom do we ask parents to participate in making a decision, because they trust us totally and ask us to decide" (D5). "It is easier for everybody, and sometimes parents are thankful, that the decision is taken by us... They want us to do everything possible and leave the decision to us ... In the end they are grateful and express their gratitude. There is no record of someone telling me, 'you have done this but you did not ask me if I wanted it to be done" (D1). "They trust us, it is extraordinary, and sometimes it is as if the baby is not their child, as if the baby was born and always lived here; like it belongs more to the hospital/institution than to his or her mother" (N3). "As a matter of fact, we may say that they [the parents] put their baby in our hands" (N6).

Some mothers confirmed that they have a high degree of trust in health professionals. A mother (coded M8) stated: "As long as we are here, it is the doctors and the nurses who take the decisions and we follow their instructions." "They know a lot more than I do and I like to help which is my part in this, as they know what should be done better than me" (M10).

Health care providers considered some decisions to be outside the realm of parental participation because of anxiety or incapacity, and therefore it is thought correct not to consult them. "In my view it is not correct to let parents take decisions concerning, for example, the interruption of ventilation in a very bad case with probable fatal outcome, where ventilation will only result in prolonging of suffering" (D4) or "If the decision is merely clinical, they cannot decide" (D10). "In normal premature babies, the parents have no say; we just inform them of what we are doing" (N11).

Informed consent, when obtained, is rarely given in writing, according to the doctors, nurses, and mothers: "No, written informed consent is not usually asked for in our unit" (D3). "In most cases, we do not ask for written informed consent and we do not see any need for it" (D4)/ "No, I never signed anything" (M11).

Informed consent is a keystone of health care ethics, and therefore it was interesting to find out that parents' exercise of their autonomy did not include providing informed consent. Written informed consent is deemed necessary whenever invasive procedures or surgeries are contemplated: "Well, when invasive procedures are indicated, they are asked to sign a form, which they do" (D1). "Only when surgery is going to take place do we ask for a written form" (D2). "Informed consent on a form signed by parents is needed before we may perform certain examinations and, of course, surgery" (N9). 


\section{Conflict Between Doctors and Parents}

The responses of most participants-health care providers and mothers-indicated that conflict about treatment choices was uncommon. When conflict was mentioned, the main source seemed to be the refusal of parents to allow inoculations or blood transfusions. "Yes, we had some situations in which we petitioned the court in order to temporarily suspend parental authority, so that we could provide a blood transfusion" (e.g., the classic case of Jehovah's Witnesses) (N5).

\section{Ethics Committee}

We were surprised to find that institutional ethics committees are seldom consulted or asked to give advice in difficult situations, since this is generally accepted as an important role of these advisory committees. The primary reason for not involving the ethics committees, according to the medical providers, was that the consultation process was considered lengthy and bureaucratic.

"It has not been necessary, and the process is sometimes bureaucratic and takes a long time" (D2). "No, we do not see any advantage in consulting our ethics committee, the answer comes months after our request and is of course totally useless" (D6). "I've never had the feeling that we needed any intervention by the ethics committee" (N3).

Six nurses did not know whether the ethics committee was heard on any issue; nine mothers were unaware of the existence of this committee.

\section{DISCUSSION}

The results of our study show that although parental rights are acknowledged by the medical team, the actual participation of parents in decision making is very limited. In no case did doctors and nurses admit the possibility of handing over decision making in important questions to parents; they made it clear that they talked to the parents, explained the possible options, and sought the parents' opinions, but that the final decision is made by the doctors (or the team, in some cases). It was not a surprise that most mothers were of the opinion that decisions should be made by doctors they trust. Some professionals, while accepting this responsibility, hesitated between the duty to give complete information and the tendency to withhold some aspects of it, especially if the prognosis was serious. On the one hand they wanted to spare the parents from anxiety and fear; on the other, they felt it was their duty to truthfully inform the parents

It is interesting to find that these attitudes are not very dissimilar from those reported by Cuttini et al. (1999), who gathered results from eight European states, as well as from those of Brinchmann and Vik (2005) in a Norwegian study. The similarity in the results suggests that there may be a European attitude that diverges from the Anglo-Saxon one, with beneficence being given more weight than autonomy in the former area. We agree with Orfali (2004), who compared French and American NICUs and stated that the fundamental question should not be that of medical paternal- ism versus parental autonomy, but rather that of deciding how and when parents should be included in the process of decision making.

Some of the doctors argue that failure to provide parents with all the information is due in part to the fact that it is difficult to know beforehand how the situation will evolve, and that to impose doubts and uncertainties on parents is not acceptable since they are already anxious about the outcome. To ask for informed consent could worsen their fears and suffering; emotionally distraught as parents are, it would be unfair to make them shoulder heavy responsibilities. Similar reasoning has been reported by Espildora (1997), McHaffie et al. (2001), Paixão (2000), and Vale et al. (2001), and Molina (2003) describes a phenomenon called "later guilt" meaning that when the outcome of parental decisions is unfavorable these parents may suffer later on from guilt, because they attribute the bad outcome to the (wrong) decision they made. However, we must state that no factual data have been presented to support the views; that is, there is no proof that excluding the parents from difficult decision making makes them more contented or happy.

Our study is subject to several limitations, the main one being the relatively small number of interviewees, which could lead to a regional bias in the results. However, the doctors and nurses interviewed had long experience in different hospitals and were responsible for the management of everyday practice in their units, which attended all cases of premature births in the whole central region of Portugal. Moreover, a multicenter research study conducted in all Portuguese NICUs showed that opinions and practice of professionals in the whole country do not significantly differ from each other (Machado et al. 2002).

Finally, our results lead us to conclude that informed consent and participation of parents in decision making is deemed neither necessary nor useful in this particular area of health care by both providers and mothers, in sharp contrast to generally accepted autonomy-based ethics. Further work should be conducted on a national and/or a multinational level, using the same kind of methodological approach. The results can then be compared to determine whether our findings represent a prevailing attitude toward the role of parents in decision making.

\section{REFERENCES}

Brinchmann, B. S., and T. Vik. 2005. Parents' involvement in lifeand-death decisions in neonatal intensive care: Norwegian attitudes. Newborn and Infant Nursing Reviews 5(2): 77-81.

Cuttini, M. et al. 1999. Parental visiting communication and participation in ethical decisions: A comparison of neonatal unit policies in Europe. Archives of Diseases in Childhood Fetal and Neonatal Edition 81: 84-91.

Espíldora, M. M. 1997. Problemas éticos en enfermería pediátrica. In Manual de ética y legislación en enfermería. Bioética de Manual de ética y legislación en enfermería. Bioética de, ed. L. P. García, and F. L. Correa, 95-97. Madrid: Mosby. 
Guba, E. G., and Y.S. Lincoln. 1994. Competing paradigms in qualitative research. In Handbook of qualitative research, ed. N. K. Denzin and Y. S. Lincoln, 105-117. London: Sage.

Machado, M. C. et al. 2002. Nascer prematuro em Portugal. Reflexões finais. In Nascer prematuro em Portugal. Estudo multicêntrico nacional 1996-2000, ed. J. C. Peixoto et al. (Grupo RN MBP), 191-197. Sl: Fundação Bial.

Maciel, A. 2003. Há mais condições para os prematuros sobreviverem com qualidade. Pais e Filhos 153: 28-32.

McHaffie, H. E. et al. 2001. Deciding for imperilled newborns: Medical authority or parental autonomy? Journal Medical Ethics 27: 104-109.

Molina, V. 2003. Consideraciones éticas en el período neonatal (VII). In Protocolos diagnosticos y terapéuticos de neonatologia en pediatria, coord. A. Delgado Rubio. <http://www.aeped.es/ protocolos/neonatologia/ index.htm $>$

Neto, M. T. et al. 2002. Politica nacional de saúde perinatal. In Nascer prematuro em Portugal. Estudo multicêntrico nacional 1996-2000, ed. J. C. Peixoto et al. (Grupo RN MBP), 15-27. Sl: Fundação Bial.
Orfali, K. 2004. Parental role in medical decision-making: Fact or fiction? A comparative study of ethical dilemmas in French and American neonatal intensive care units. Social Science\& Medicine 58 2009-2022.

Paixão, A. 2000. Problemas éticos no princípio da vida humana: Cuidados intensivos neonatais. Cadernos de Bioética 24: 41-49.

Pellico, M. G. 2002. Decisiones difíciles en neonatología. Una aproximación ética. In Bioética: Un diálogo plural. Homenaje a Javier Gafo Fernández, ed. J. J. Ferrer and J. L. Martinez, 97-115. Madrid: Universidad Pontificia Comillas

Portugal. 2006. Estatísticas demnográficas 2005. Lisboa: INE.

Rousseau, N., and F. Saillant. 1999. Abordagens de investigação qualitativa. In $O$ processo de investigação: Da concepção à realização, ed. M. F. Fortin, 147-160. Loures: Lusociência.

Silva, E. B. 2007. Prematuridade: Questões éticas. PhD thesis in bioethics. Porto: Universidade Católica Portuguesa, Instituto de Bioética.

Vale, M. C. et al. 2001. Mortalidade numa unidade de cuidados intensivos pediátricos. Análise e consideraçōes éticas. Acta Pediátrica Portuguesa 32(2): 77-82. 